\title{
Knowledge and perceptions of air pollution in Ningbo, China
}

\author{
Xujun Qian ${ }^{1,2}$, Guozhang Xu ${ }^{3}$, Li Li ${ }^{1}$, Yueping Shen ${ }^{2 *}$, Tianfeng He ${ }^{3^{*}}$, Yajun Liang ${ }^{4}$, Zuyao Yang ${ }^{5}$, \\ Wan Wei Zhou ${ }^{6}$ and Jiaying $\mathrm{Xu}^{6}$
}

\begin{abstract}
Background: The residents' knowledge, attitudes and practices related to ambient air pollution and health will help to improve the understanding of environmental protection and make environmental health policies more targeted and effective. This study aimed at knowing the attitudes and behaviors towards ambient air pollution and health.

Methods: A cross-sectional survey was conducted in Ningbo, China in January 2015. Personal information and questions pertaining to the knowledge, attitudes and practices towards ambient air pollution and health were collected through questionnaire investigations. Descriptive statistics, chi-square tests and multiple unconditional logistic regression analysis were used.

Results: The questionnaire was completed by 1604 respondents (59.41\% women). The awareness rate was $64.59 \%$ and varied significantly with age, levels of education, and occupation (all $p<0.05$ ). Only $5.80 \%$ of the total participants were satisfied with the air quality in Ningbo in 2014. Most respondents (78.80\%) expressed concern about the possible aggravation of the haze. More than $80 \%$ of participants believed that it will take at least 3-5 years or longer before the air quality is improved. Television and internet resources have replaced books and newspapers as the primary sources for obtaining knowledge about haze and related protective measures. $85.22 \%$ of respondents were concerned about air quality index (AQI). Most of the residents have taken protective measures indoors during haze weather. $48.50 \%$ have worn face masks when going outside, the most frequently type of face masks selected were cotton (39.85 \%) or gauze face masks (36.24\%). Age and occupation were the main factors associated with the level of knowledge about air pollution $(p<0.05)$.

Conclusions: There were a relatively high knowledge awareness rate, strong health protection consciousness and high enthusiasm for air pollution control among Ningbo residents. The elderly people and less-educated residents are the targetable population for improving environment.
\end{abstract}

Keywords: Haze/ambient air pollution, Health, Knowledge attitudes and practices

\section{Background}

Ambient air pollution is an increasingly severe public health problem worldwide, especially in China, where environmental deterioration has accompanied rapid economic growth, causing concern both domestically and internationally. The Global Burden of Disease study has confirmed that ambient air pollution is a leading risk factor for adverse health [1-3]. Policies on ambient air

\footnotetext{
*Correspondence: shengyuepingsz@126.com; tfhe0@sohu.com

${ }^{2}$ School of Public Health, Soochow University, \#199, Renai Road, Industrial

Park District, Suzhou 215123, China

${ }^{3}$ Ningbo Municipal Center for Disease Control and Prevention, \#237,

Yongfeng Road, Haishu District, Ningbo 315010, China

Full list of author information is available at the end of the article
}

pollution have been implemented to monitor China's serious problem of haze-fog pollution. It will be a long time before the results of these policies are fully known. Valid and reliable estimates of demographic correlates of knowledge, attitudes and practices (KAP) of ambient air pollution on health are essential to support evidence based government policy in this important area $[1,4]$.

Ningbo, a coastal city located on the eastern coast of China, is relatively developed economically and is one of the busiest port cities in the Yangtze River delta. High levels of haze were experienced for 96 days in 2012, 138 days in 2013 [5]. Ambient air pollution reached "hazardous" levels for eight days in December 2013. 
Therefore, ambient air pollution in Ningbo is a growing public health problems concern.

A KAP survey is a representative study of a specific population that aims to collect data on what is known, believed and done in relation to a particular topic [6]. It is a crucial element of ambient air pollution control, as little information was available about residents' KAP of ambient air pollution and health in China. Although several studies have investigated public awareness about ambient air pollution and its adverse health effects in some cities, investigation of Ningbo has not been conducted. This study focused on Ningbo as an example to understand and identify factors associated with the residents' knowledge of current ambient air pollution, their attitudes toward air pollution control, and the practices of protection in Ningbo. This information could be vital for the local government in regard to the development of more impactful policies and effective measures to reduce air pollution in the future.

\section{Methods}

\section{Study participants}

The household interview was conducted in January 2015. A multistage cluster-sampling method was employed to identify study participants. Generally speaking, there are significant differences between urban and rural area in economic and cultural level in China. To make the study more representative, the sampling frame used in the first stage defines primary sampling units (PSU) as either districts that represent urban or counties that represent rural areas. Then one urban district (Jiangbei) and one rural county (Ninghai) were randomly selected respectively from six districts and five counties of Ningbo. In the second-stage sampling units (SSU), two residential streets in each of the selected district and county were identified as the sample areas. Formula for estimating sample size as follows: $N=\operatorname{deff} \times \frac{1.96^{2} \hat{p} \hat{q}}{d^{2}}$, where deff is the design effect, $\hat{p}$ is the estimator of a proportion, $p=0.5, \mathrm{q}=0.5 . \mathrm{d}=0.1$,

$$
N=2 \times \frac{1.96^{2}(0.5)(0.5)}{0.1^{2}}=192.08=193
$$

in the study, we increased the minimum sample size by $10 \%$ to make up for the lack of questionnaire design. Hence, the final sample size for each residential street was 212 households. There were four residential streets in the study, so 848 households were selected. In each household family members aged 14 to 65 years, registered permanent ningbo residence (living at their present residence for more than one year in Ningbo before this survey) were screened undergo the interview. Overall, 1680 participants were approached, of whom 1604 responded (responserate:95.47\%).

\section{Questionnaire investigation}

We conducted the survey in a face-to-face interview style to assess the residents' KAP with regard to the effects of haze-fog pollution on health. The validity of the questionnaire was established through content and expert validity, The internal consistency of knowledge outcomes were tested by Cronbach's alpha. A 24-item questionnaire designed by public health experts was used, focusing primarily on three kinds of questions: demographic characteristics (e.g., age, gender, educational level, residence, average annual household income, occupation, etc.), knowledge (e.g., The question was "what health problems do you think are brought about by air pollution?". The response alternatives were "lung cancer","difficulty breathing", "heart problems" or "I'm not sure".) and attitudes (e.g., The question was "Were you satisfied with the air quality in Ningbo last year?". The response alternatives were "yes","no" or "I do not care about this problem at all") towards ambient air pollution, and behavior related to the ambient air pollution. There contains five questions about knowledge related to the haze and heath. The scores varied from $0-5$ points, each right answer was given a score of 1 and the wrong answer was given a score of 0 . Residents who gave the right answer to all questions were classified into the "known" level and those who failed to any one question were classified into the "unknown" level. We defined the awareness rate of knowledge as the percentage of respondents who were classified into the "known" level.

\section{Data analysis}

Epidata 3.02 was applied to establish a database, and double data entry was used to reduce errors. SAS 9.2 was used for statistical analyses. Chi-square tests were applied for demographic factors including respondents' gender, age groups, educational level and occupation. Multiple unconditional logistic regression was used to assess the associations between knowledge outcome and demographic factors, with adjusted odds ratios (ORs) and $95 \%$ confidence intervals (CIs) being presented. $p<0.05$ was considered as statistically significant.

\section{Results}

Of the 1604 subjects, $40.59 \%$ were males and $59.41 \%$ were females. The mean age of respondents was 39.31 years (range from 14 to 65 years) with a standard deviation of 14.36 years. Table 1 shows the general demographic characteristics.

The Cronbach's alpha values for testing the internal consistency of knowledge outcomes were between 0.655 and 0.827 . The awareness rate in respect of the haze and its adverse effects on health was $64.59 \%(1036 / 1604)$. There was statistically significant difference in the awareness between urban and rural areas as well as age 
Table 1 Demographic characteristics of the interviewees $(n=1604)$

\begin{tabular}{|c|c|c|c|c|c|c|}
\hline Characteristics & Frequency $(\mathrm{n})$ & Percentage (\%) & Frequency of awareness (n) & Awareness rate (\%) & $x^{2}$ & $P$ value \\
\hline \multicolumn{7}{|l|}{ Districts } \\
\hline Jiangbei Districts & 852 & 53.11 & 599 & 70.31 & \multirow[t]{2}{*}{25.96} & \multirow[t]{2}{*}{$<0.0001$} \\
\hline Ninghai County & 752 & 46.89 & 437 & 58.11 & & \\
\hline \multicolumn{7}{|l|}{ Gender } \\
\hline Male & 651 & 40.59 & 413 & 63.44 & \multirow[t]{2}{*}{0.63} & \multirow[t]{2}{*}{0.4270} \\
\hline Female & 953 & 59.41 & 623 & 65.37 & & \\
\hline \multicolumn{7}{|l|}{ Age (years) } \\
\hline $14-$ & 478 & 29.80 & 362 & 75.73 & \multirow[t]{5}{*}{111.33} & \multirow[t]{5}{*}{$<.0001$} \\
\hline $30-$ & 411 & 25.62 & 297 & 72.26 & & \\
\hline $40-$ & 249 & 15.52 & 165 & 66.27 & & \\
\hline $50-$ & 271 & 16.90 & 121 & 44.65 & & \\
\hline$\geq 60$ & 195 & 12.16 & 91 & 46.67 & & \\
\hline \multicolumn{7}{|l|}{ Education } \\
\hline$\geq$ College & 755 & 47.07 & 561 & 74.30 & \multirow[t]{4}{*}{100.78} & \multirow[t]{4}{*}{$<.0001$} \\
\hline High school & 355 & 22.13 & 242 & 68.17 & & \\
\hline Junior high school & 313 & 19.51 & 155 & 49.52 & & \\
\hline$\leq$ Elementary school & 181 & 11.28 & 78 & 43.09 & & \\
\hline \multicolumn{7}{|l|}{ Occupation } \\
\hline Manual worker & 141 & 8.79 & 78 & 55.32 & \multirow[t]{6}{*}{128.72} & \multirow[t]{6}{*}{$<.0001$} \\
\hline Homemaker and retired & 350 & 21.82 & 147 & 42.00 & & \\
\hline Student & 182 & 11.35 & 149 & 81.87 & & \\
\hline Cadre and technician & 583 & 36.35 & 426 & 73.07 & & \\
\hline Service & 287 & 17.89 & 199 & 69.34 & & \\
\hline Unemployed & 61 & 3.80 & 37 & 60.66 & & \\
\hline
\end{tabular}

groups $(p<0.05)$. In addition, awareness declined significantly with increasing age, but increased significantly with the increasing levels of education $(p<0.05)$. There was also significant difference among occupation groups, with students demonstrating the highest level of awareness, accounting for $81.87 \%(p<0.05)$. But no statistically significant difference was found in the awareness between men and women $(p>0.05)$ (Table 1).

\section{Attitudes}

Of those 1604 residents, only $5.80 \%$ were satisfied with the air quality in Ningbo in 2014. The majority of residents paid attention to ambient air pollution, accounting for $78.24 \% .21 .13 \%$ of residents believed the rate of the haze in Ningbo was "high". To the possible aggravation of the haze, $78.80 \%$ of the residents expressed that they "worry about", while $16.34 \%$ expressed "do not worry about". $15.96 \%$ of residents thought that the haze will improve in the short-term, $57.92 \%$ of the residents believe that the haze will improve within 3-5 years, while $26.12 \%$ of the residents believed the haze will take at least 10 years to improve. $45.08 \%$ of the respondents agreed that the government should take primary responsibility for the haze, while $42.83 \%$ believed that every citizen should take primary responsibility for improving the haze. The sources of haze information most commonly reported in this study were from television and internet resources, accounting for $57.42 \%$, while $22.88 \%$ of the residents from books and newspapers, and $19.70 \%$ from expert lecture and friends (Table 2).

\section{Practices}

The percentage of residents' practices taken during hazy conditions is summarized in Table 3. Among the 1604 residents, $66.77 \%(1071 / 1064)$ of them have taken protective measures indoors, and most of them have taken measures such as using air purifiers, putting up green plants, using activatedcarbon and so on. $74.32 \%$ (1192/ 1604) have reduced or eliminated outdoor exercise. $67.33 \%(1080 / 1604)$ have cut down travel during weekends. $66.46 \%(1066 / 1604)$ have reduced times of opening windows to air the room. $85.22 \%(1367 / 1604)$ were concerned about air quality index (AQI). When be asked whether wearing face masks or not when going outside, half of them $(51.50 \%, 826 / 1604)$ answered 'no'. And another part of them, $48.50 \%(778 / 1604)$ have worn face 
Table 2 The attitudes of the haze and related health risk

\begin{tabular}{|c|c|c|}
\hline Survey content & $\mathrm{N}$ & $\%$ \\
\hline \multicolumn{3}{|l|}{$\begin{array}{l}\text { Were you satisfied with the } \\
\text { air quality in Ningbo last year? }\end{array}$} \\
\hline Yes & 93 & 5.80 \\
\hline No & 641 & 39.96 \\
\hline Average & 870 & 54.24 \\
\hline \multicolumn{3}{|c|}{$\begin{array}{l}\text { Have you paied attention to the } \\
\text { haze in the community where you live? }\end{array}$} \\
\hline Yes & 1255 & 78.24 \\
\hline No & 68 & 4.24 \\
\hline Indifferent & 281 & 17.52 \\
\hline \multicolumn{3}{|c|}{$\begin{array}{l}\text { How severe would you say is the } \\
\text { haze in the community where you live? }\end{array}$} \\
\hline Low & 332 & 20.70 \\
\hline Moderate & 933 & 58.17 \\
\hline High & 339 & 21.13 \\
\hline \multicolumn{3}{|c|}{$\begin{array}{l}\text { How would you feel about the } \\
\text { possible aggravation of the haze? }\end{array}$} \\
\hline Worry about & 1264 & 78.80 \\
\hline Do not worry about & 262 & 16.34 \\
\hline No concern of mine & 78 & 4.86 \\
\hline \multicolumn{3}{|l|}{$\begin{array}{l}\text { How long do you think it will } \\
\text { take for air quality to improve? }\end{array}$} \\
\hline In the short-term & 256 & 15.96 \\
\hline Within 3-5 years & 929 & 57.92 \\
\hline At least 10 years & 419 & 26.12 \\
\hline \multicolumn{3}{|c|}{$\begin{array}{l}\text { Whom do you think should be } \\
\text { primary responsible for the haze? }\end{array}$} \\
\hline The government & 723 & 45.08 \\
\hline Every citizen & 687 & 42.83 \\
\hline The industries & 194 & 12.09 \\
\hline \multicolumn{3}{|c|}{$\begin{array}{l}\text { What is your favorites way to obtain } \\
\text { knowledge refer to the haze and } \\
\text { related protective measures? }\end{array}$} \\
\hline Television and internet & 921 & 57.42 \\
\hline Books and newspapers & 367 & 22.88 \\
\hline Expert lecture and friends & 316 & 19.70 \\
\hline
\end{tabular}

masks, the most frequently type of face masks selected by them were cotton $(39.85 \%, 310 / 778)$ or gauze face masks $(36.24 \%, 282 / 778)$. Minor of them have chosen N95 face masks $(8.10 \%, 63 / 778)$.

\section{Variables associated with awareness rate}

The demographic factors associated with awareness rate used multiple unconditional logistic regression analysis are shown in Table 4. Two variables had a significant influence on knowledge awareness rate: age and occupation. Taking "age 14-29" as the baseline group, the knowledge awareness rate of age 30-39, 40-49, 50-59,
Table 3 Percentage of residents' practices taken in haze weather

\begin{tabular}{lll}
\hline Survey content & $\mathrm{N}$ & $\%$ \\
\hline $\begin{array}{l}\text { Related protective measures } \\
\text { taken indoors }\end{array}$ & & \\
Yes & 1071 & 66.77 \\
No & 533 & 33.23
\end{tabular}

What related protective measures

have you taken indoors?

(multiple choice)

Use of air purifiers
Putting green plants
Putting activated carbon
Others

$\begin{array}{ll}342 & 16.43 \\ 827 & 47.90 \\ 281 & 26.24 \\ 101 & 9.43\end{array}$

Reduce or eliminated outdoor exercise

$\begin{array}{lll}\text { Yes } & 1192 & 74.32 \\ \text { No } & 412 & 25.68\end{array}$

Cut down travel during weekend

$\begin{array}{lll}\text { Yes } & 1080 & 67.33 \\ \text { No } & 524 & 32.67\end{array}$

Reduce times of opening windows to air the room

$\begin{array}{lll}\text { Yes } & 1066 & 66.46\end{array}$

$\begin{array}{lll}\text { No } & 538 & 33.54\end{array}$

Concern or learn about air quality index

$\begin{array}{lll}\text { Yes } & 1367 & 85.22\end{array}$

$\begin{array}{lll}\text { No } & 237 & 14.78\end{array}$

Wear face masks when going outside

$\begin{array}{lll}\text { Yes } & 778 & 48.50\end{array}$

No $\quad 826 \quad 51.50$

Which type of face masks do you used?

Cotton face masks $\quad 310 \quad 39.85$

Gauze face masks $\quad 282 \quad 36.24$

N95 face masks $\quad 63 \quad 8.10$

$\begin{array}{lll}\text { others } & 123 & 15.81\end{array}$

and $\geq 60$ groups were lower, In other words, those who were 14-29 years old were the most likely to have a high level of knowledge. Assigning the highest knowledge awareness rate occupation group "Student" as the baseline group, the knowledge awareness rate of other groups were lower.

\section{Discussion}

Previous studies have shown low knowledge awareness rate $(27.9 \%)$ about particulate matter that has an aerodynamic diameter of 2.5 microns or smaller $\left(\mathrm{PM}_{2.5}\right)$ in Guangzhou residents [7]. But in this survey, Ningbo residents showed a higher awareness level at the haze and 
Table 4 Odd ratios and confidence interval of variables associated with awareness rate in multiple unconditional logistic regression analysis

\begin{tabular}{lllll}
\hline Characteristics & $\beta$ & OR & OR 95 \% Cl & $P$ value \\
\hline Age group & & & & \\
$\quad$ 14-29(reference) & & 1 & $0.00-0.00$ & \\
30-39(1) & 0.18 & 1.19 & $0.88-1.60$ & 0.26 \\
$40-49(2)$ & 0.45 & 1.58 & $1.13-2.20$ & $<0.01$ \\
$50-59(3)$ & 1.34 & 3.84 & $2.79-5.27$ & $<0.01$ \\
60-(4) & 1.26 & 3.54 & $2.49-5.02$ & $<0.01$ \\
Occupation group & & & & \\
Student(reference) & & 1 & $0.00-0.00$ & \\
Cadre and technician(1) & 0.48 & 1.62 & $1.07-2.45$ & $<0.05$ \\
Service(2) & 0.66 & 1.94 & $1.24-3.04$ & $<0.01$ \\
$\quad$ Unemployed(3) & 1.04 & 2.84 & $1.51-5.36$ & $<0.01$ \\
Manual worker(4) & 1.26 & 3.54 & $2.15-5.83$ & $<0.01$ \\
Homemaker and retired(5) & 1.80 & 6.05 & $3.94-9.29$ & $<0.01$ \\
\hline
\end{tabular}

${ }^{\text {a }} \mathrm{Cl}$ confidence interval, $O R$ odds ratio. Note: assigned "the score of knowledge $\geq 5$ " to 1 , others to 0 ; Assigned "age 14-29" to 0 (reference group), "30-39" = 1, " $40-49 "=2$, "50-59" = 3, " $\geq 60$ " = 4; Assigned "occupation group Student" to 0 (reference group), "Cadre and technician" =1,"Service" = 2;

"Unemployed" $=3$, "Manual worker" $=4$, "Homemaker and retired" $=5$

its adverse impact on health despite experiencing a lower level of exposure to ambient air pollution in China. It indicates that Ningbo residents have a certain understanding on hazy-fog pollution and its adverse impact on health. This is primarily due to Ningbo suffering from widespread heavy smog and hazardous levels of particle pollution twice in 2013 [5], which enabled the local residents to have a better understanding of ambient air pollution. Even the elderly have good understanding of the professional vocabulary like $\mathrm{PM}_{2.5}$. In addition, rising standards of living also contributes to the demand for improved air quality. And what should be acknowledged is that the differences between the known and unknown levels definition about the haze and its adverse impact on health might affect the awareness rate.

Although not many residents were satisfied with the air quality in Ningbo in 2014, only $21.13 \%$ of residents believed the haze in Ningbo was "serious". This is mainly because Ningbo's air quality is relatively good compared with other major China cities. Ningbo's environmental air quality have been ranked 15th according to the air quality comprehensive index among the first 74 key cities executing the new air quality standards, and have been the 4th among the 25 major cities located in the Yangtze River Delta, better than Shanghai, Nanjing, Hangzhou and Suzhou in 2014 [8]. According to the related reference, the annual average concentration of $\mathrm{PM}_{2.5}$ was $46 \mu \mathrm{g} / \mathrm{m}^{3}$ in Ningbo in 2014, which was much lower than that in cities such as Beijing $\left(72.6 \mu \mathrm{g} / \mathrm{m}^{3}\right)$, Xi'an $\left(78 \mu \mathrm{g} / \mathrm{m}^{3}\right)$ [9]. Although rarely will the city be shrouded by the extreme haze weather, the issues involved with healthy air quality grow year by year. Scince People intuitively feel the change, the majority of residents paied attention to the haze in the community where they live and worried about the possible aggravation of the haze. But it is inspiring to see that $57.92 \%$ of residents considered the air pollution be improved within 3-5 years, they also felt that both the government and individuals have an equal responsibility to improve the air quality. This demonstrates that the residents express a strong desire to engage, support and participate in the activity of governing the haze-fog pollution. Television and the internet are replacing traditional newspapers and expert lecture as the most common ways to obtain knowledge about ambient air pollution, a result consistent with findings reported in the survey in Beijing [10]. This illustrates changes in the way information is disseminated with the development of society. Residents are more inclined to use more visual, auditory and intuitive ways to obtain information, suggesting government meet various kinds of demands for residents such as resources in local dialect for the elderly and simplified materials for less educated people in order to improve the effect of environmental health publicity and education.

In this study, during haze weather, most of the residents have taken some protective measures indoors, such as using air purifiers, putting up green plants, using activated carbon and so on. Reducing outdoor exercise and weekend travel, learning about AQI and wearing face masks were also important measures for the residents to protect themselves from the haze. All these practices have indicated that certain self protection consciousness seems to be developing. But on the choice of the face masks, the most frequently type of face masks selected by those residents were cotton or gauze face masks that used to break the wind rather than antismog face masks that offer protective effects. According to some studies, the cotton and gauze face masks provide poor protection against the haze. [11-13]. Epidemiological studies demonstrate that no lower "safe" threshold of exposure seems to exist at the population level $[14,15]$. The European Commission (EC) acknowledges that the current standards are insufficient for the protection of public health, particularly in reference to the World Health Organization (WHO) air quality guidelines [16]. Moreover, levels of air pollution remain high and are increasing in China [17]. Therefore interventions which separate people from pollution as components of formal strategies are of great importance. However, they have been largely overlooked according to an international multidisciplinary workshop [18]. Evidence has shown that interventions can reduce air pollutants exposure, especially measures such as air filtration, closing 
windows and air conditioning, using a particulate respirator face mask. These measures are shown to be feasible and effective [19]. Therefore, strategic priorities should go beyond reducing national level of outdoor ambient concentrations. They should address the effects of specific policy as well as the protective role of masks and air purifiers.

Univariate and multivariate logistic regression analysis in this study showed a correlation between residents' age, occupation, educational level and knowledge awareness rate of air pollution. In this study those who were more educated were associated with higher awareness level and were more likely to pay attention to the negative health effects from air pollution exposure, which was consistent with most previous studies [20-23]. On the other hand, a study had shown no significant associations between education level and high degree of concern with air pollution [24], but a study from the United States indicated individuals with lower income and educational attainment appear to have been more perceptive and responsive to air quality [25]. Thus, further studies are needed to clarify these issues.

Controversy exists with regards to the association of the knowledge awareness rate with age, this study indicated that the awareness rate of haze in the youth was significantly higher than that in the elderly. There are studies that have not found a significant association between age and perceptions of air quality [26, 27]. Different connections observed in another study found that young respondents pay more attention to environmental issues while the elderly emphasize health and safety [28]. Other studies found that the youth had poor awareness rate compared to the elderly $[10,22]$. Most of the studies have not given a clear explanation for these differences. Further research needs to investigate the interaction between age and awareness rate of air pollution.

When comparing the residents' occupations, in this study, the retired and the manual laborer showed a lower degree of concern and awareness rate than those groups like the student, the cadre and technician. This may be due to influencing factors of education level, economical status and social status.

The relationship between age, education and awareness rate is controversial, recent studies could not provide a clear explanation for these differences. This could be due to a lack of a uniform assessment criteria for knowledge awareness rate, the different control of age of research subjects. Thus, further research is needed to help understand factors shaping people's awareness.

\section{Conclusions}

Although Ningbo residents are exposed to relatively lower level ambient air pollution than the rest of the nation, it showed a large percentage of residents are aware of the haze problem and the correlation between air pollution and health. However, knowledge was still relatively low in some groups, such as the less educated, the elderly and some type of occupation. This may help policymakers make targeted advocacy and guidance to make residents aware of sources of air pollution and related health risks.

\section{Abbreviations \\ AQI: Air quality index; Cl: Confidence interval; KAP: Knowledge, attitudes and practices; OR: Odds ratio; $\mathrm{PM}_{2.5}$ : Particulate matter that has an aerodynamic diameter of 2.5 microns or smaller; WHO: World Health Organization}

\section{Acknowledgements \\ We thank the Jiangbei District Center for Disease Control and Prevention and Ninghai County Center for Disease Control and Prevention for their support of this research. We also would like to thank our respondents for their invaluable contribution to this study.}

\section{Funding}

This work was supported by grants from the Medical Technology Program Foundation of Zhejiang (2014KYA202), Program of Innovative Research Team of Ningbo Science and Technology Bureau (2012B82018-10) and Science and Technology Program of Ningbo, China (2014C50027, 2015C50056).

\section{Availability of data and materials}

Report of data analysis undertaken and a copy of the survey instrument during this study are available from the corresponding author on reasonable request.

\section{Authors' contributions}

$\mathrm{XQ}$ designed the study, performed preliminary statistical analysis, interpreted results, drafted the initial manuscript, and submitted the final manuscript. GX aided in creating the KAP survey, collected data and revised manuscript critically for important content. LL provided constructive advice and guidance in the revised manuscript of important content. YS (Cocorresponding author) designed the study and performed final statistical analysis of the data for publication. TH (Co-corresponding author) designed the study and and submitted the final manuscript. YL drafted manuscript for submission. ZY created survey materials, drafted manuscript for submission. WWZ revised manuscript critically for important content. JX improved the revised manuscript and made some linguistic revision. All authors read and approved the final manuscript.

\section{Competing interests}

The authors declare that they have no competing of interests.

\section{Consent for publication}

Not applicable.

\section{Ethics approval and consent to participate}

The survey protocols, instruments, and the process for obtaining the informed consent for participants were approved by the ethics committee of Ningbo Municipal Center for Disease Control and Prevention. All participants provided written informed consents prior to the surveys.

\section{Author details}

${ }^{1}$ Ningbo First Hospital, Ningbo 315010, China. ${ }^{2}$ School of Public Health, Soochow University, \#199, Renai Road, Industrial Park District, Suzhou 215123, China. ${ }^{3}$ Ningbo Municipal Center for Disease Control and Prevention, \#237, Yongfeng Road, Haishu District, Ningbo 315010, China. ${ }^{4}$ Department of Epidemiology, Capital Institute of Pediatrics, Beijing, China. ${ }^{5}$ Division of Epidemiology, JC School of Public Health and Primary Care, The Chinese University of Hong Kong, Shatin, NT, Hong Kong, SAR, China. ${ }^{6}$ Department of public Health and Tropical Medicine, Tulane University, New Orleans, LA, USA.

Received: 29 September 2015 Accepted: 20 October 2016 Published online: 05 November 2016 


\section{References}

1. Lim SS, Vos T, Flaxman AD, Danaei G, Shibuya K, Adair-Rohani H, Amann M, Anderson HR, Andrews KG, Aryee M, et al. A comparative risk assessment of burden of disease and injury attributable to 67 risk factors and risk factor clusters in 21 regions, 1990-2010: a systematic analysis for the Global Burden of Disease Study 2010. Lancet. 2012;380(9859):2224-60.

2. WHO (2014) 7 million deaths annually linked to air pollution. http://www. who.int/phe/health_topics/outdoorair/databases/en/. Accessed 9 Jul 2014.

3. Landrigan PJ, Fuller R. Global health and environmental pollution. Int J Public Health. 2015;60(7):1-2.

4. Johnston FH, Hanigan IC, Henderson SB, Morgan GG. Evaluation of interventions to reduce air pollution from biomass smoke on mortality in Launceston, Australia: retrospective analysis of daily mortality, 1994-2007. BMJ. 2013;346:e8446

5. Xiu-li JL-IX, Yang H. Analysis and countermeasures on fog and haze in Ningbo. Environ Sci Manage. 2015;40(2):43-6.

6. Zahedi L, Sizemore E, Malcolm S, Grossniklaus E, Nwosu O. Knowledge, attitudes and practices regarding cervical cancer and screening among Haitian health care workers. Int J Environ Res Public Health. 2014:11(11):11541-52.

7. Gu J-n, Ma W-j, Wang T-q, Zhang D-s, Zhou Q, Liu Z-h, Cai W-f, Liu S-f. Survey of knowledge, attitude and behavior related to PM2. 5 among 605 residents in Guangzhou City. South China J Prev Med. 2013;39(4):6-10.

8. Ningbo Environmental Protection Bureau (2015): 2014 Report on the State of Ningbo Minicipal Environment. http///www.nbepb.gov.cn/. Accessed 4 June 2015.

9. Li GX, Pan XC. Evaluation of excess mortality caused by PM2.5 in four typical Chinese big cities. Natl Med J China. 2013;93(34):2703-6.

10. Pei J, Li-guo C. Investigation on defense capability and information needs of Haze/fog in Changping District, Beijing. Chinese J Health Educ. 2014;30(12):1076-9.

11. McCullough NV, Brosseau LM, Vesley D. Collection of three bacterial aerosols by respirator and surgical mask filters under varying conditions of flow and relative humidity. Ann Occup Hyg. 1997;41(6):677-90.

12. Balazy A, Toivola M, Adhikari A, Sivasubramani SK, Reponen T, Grinshpun SA. Do N95 respirators provide 95\% protection level against airborne viruses, and how adequate are surgical masks? Am J Infect Control. 2006;34(2):51-7.

13. Rengasamy A, Zhuang Z, BerryAnn R. Respiratory protection against bioaerosols: Literature review and research needs. Am J Infect Control. 2004;32(6):345-54.

14. Crouse DL, Peters PA, van Donkelaar A, Goldberg MS, Villeneuve PJ, Brion O, Khan S, Atari DO, Jerrett M, Pope CA, et al. Risk of nonaccidental and cardiovascular mortality in relation to long-term exposure to low concentrations of fine particulate matter: a Canadian national-level cohort study. Environ Health Perspect. 2012;120(5):708-14.

15. Lepeule J, Laden F, Dockery D, Schwartz J. Chronic exposure to fine particles and mortality: an extended follow-up of the Harvard Six Cities study from 1974 to 2009. Environ Health Perspect. 2012;120(7):965-70

16. Heroux ME, Anderson HR, Atkinson R, Brunekreef B, Cohen A, Forastiere F, Hurley F, Katsouyanni K, Krewski D, Krzyzanowski M, et al. Quantifying the health impacts of ambient air pollutants: recommendations of a WHO/ Europe project. Int J Public Health. 2015;60(5):619-27.

17. van Donkelaar A, Martin RV, Brauer M, Boys BL. Use of satellite observations for long-term exposure assessment of global concentrations of fine particulate matter. Environ Health Perspect. 2015;123(2):135-43.

18. Giles LV, Barn P, Kunzli N, Romieu I, Mittleman MA, van Eeden S, Allen R, Carlsten C, Stieb D, Noonan C, et al. From good intentions to proven interventions: effectiveness of actions to reduce the health impacts of air pollution. Environ Health Perspect. 2011;119(1):29-36.

19. Morishita M, Thompson KC, Brook RD. Understanding air pollution and cardiovascular diseases: is it preventable? Curr Cardiovasc Risk Rep. 2015;9(6):1-9.

20. Wang R, Yang Y, Chen R, Kan H, Wu J, Wang K, Maddock JE, Lu Y. Knowledge, attitudes, and practices (KAP) of the relationship between air pollution and children's respiratory health in Shanghai, China. Int J Environ Res Public Health. 2015;12(2):1834-48.

21. Stieb DM, Paola J, Neuman K. Do smog advisories work? Results of an evaluation of the Canadian Smog Advisory Program. Can J Public Health = Revue canadienne de sante publique. 1996:87(3):166-9.

22. Kim M, Yi O, Kim H. The role of differences in individual and community attributes in perceived air quality. Sci Total Environ. 2012;425:20-6.

23. Jacquemin B, Sunyer J, Forsberg B, Gotschi T, Bayer-Oglesby L, AckermannLiebrich U, de Marco R, Heinrich J, Jarvis D, Toren K, et al. Annoyance due to air pollution in Europe. Int J Epidemiol. 2007;36(4):809-20.
24. Rotko T, Oglesby L, Künzli N, Carrer P, Nieuwenhuijsen MJ, Jantunen M. Determinants of perceived air pollution annoyance and association between annoyance scores and air pollution (PM2.5, NO2) concentrations in the European EXPOLIS study. Atmos Environ. 2002;36(29):4593-602.

25. Semenza JC, Wilson DJ, Parra J, Bontempo BD, Hart M, Sailor DJ, George LA. Public perception and behavior change in relationship to hot weather and air pollution. Environ Res. 2008;107(3):401-11.

26. Egondi T, Kyobutungi $\mathrm{C}, \mathrm{Ng} \mathrm{N}$, Muindi $\mathrm{K}$, Oti $\mathrm{S}$, van de Vijver $\mathrm{S}$, Ettarh $\mathrm{R}$, Rocklov J. Community perceptions of air pollution and related health risks in Nairobi slums. Int J Environ Res Public Health. 2013;10(10):4851-68.

27. Zhang L, Yuan Z, Maddock JE, Zhang P, Jiang Z, Lee T, Zou J, Lu Y. Air quality and environmental protection concerns among residents in Nanchang, China. Air Qual, Atmosphere Health. 2014;7(4):441-8.

28. Fischer GW, Morgan MG, Fischhoff B, Nair I, Lave LB. What risks are people concerned about. Risk Anal. 1991;11(2):303-14.

\section{Submit your next manuscript to BioMed Central and we will help you at every step:}

- We accept pre-submission inquiries

- Our selector tool helps you to find the most relevant journal

- We provide round the clock customer support

- Convenient online submission

- Thorough peer review

- Inclusion in PubMed and all major indexing services

- Maximum visibility for your research

Submit your manuscript at www.biomedcentral.com/submit
O Biomed Central 